\title{
Wittgenstein as a Philosopher of Technology: Tool Use, Forms of Life, Technique, and a Transcendental Argument
}

\author{
Mark Coeckelbergh $^{1}$ (D) Michael Funk ${ }^{1}$
}

Published online: 12 January 2018

(C) The Author(s) 2018. This article is an open access publication

\begin{abstract}
The work of Ludwig Wittgenstein is seldom used by philosophers of technology, let alone in a systematic way, and in general there has been little discussion about the role of language in relation to technology. Conversely, Wittgenstein scholars have paid little attention to technology in the work of Wittgenstein. In this paper we read the Philosophical Investigations and On Certainty in order to explore the relation between language use and technology use, and take some significant steps towards constructing a framework for a Wittgensteinian philosophy of technology. This framework takes on board, and is in line with, insights from postphenomenological and hermeneutic approaches, but moves beyond those approaches by benefiting from Wittgenstein's insights into the use of tools, technique, and performance, and by offering a transcendental interpretation of games, forms of life, and grammar. Focusing on Wittgenstein's philosophy of language in the Investigations, we first discuss the relation between language use and technology use, understood as tool use, by drawing on his analogy between language and tools. This suggests a more general theory of technology use, understood as performance. Then we turn to his epistemology and argue that Wittgenstein's understanding of language use can be embedded within a more general theory about technology use understood as tool use and technique, since language-in-use is always already a skilled and embodied technological practice. Finally, we propose a transcendental interpretation of games, forms of life, and grammar, which also gives us a transcendental way of looking at technique, technological practice, and performance. With this analysis and interpretation, further supported by comments on robotics and music, we contribute to using and
\end{abstract}

Mark Coeckelbergh

mark.coeckelbergh@univie.ac.at

Michael Funk

michael.funk@univie.ac.at

1 Department of Philosophy, University of Vienna, Vienna, Austria 
integrating Wittgenstein in a more systematic way within philosophy of technology and engage with perennial questions from the philosophical tradition.

Keywords Wittgenstein · Philosophy of technology · Philosophical investigations - Language - Knowledge - Material hermeneutics · Postphenomenology · Embodiment · Technique · Performance · Form of life - Transcendental · Grammar

\section{Introduction: Gaps in Philosophy of Technology and Wittgenstein Scholarship (Act 1)}

The work of Ludwig Wittgenstein is not very often used in philosophy of technology. Moreover, in philosophy of technology little attention has been paid to the relation between language and philosophy (Coeckelbergh 2015, 2017). One exception is Winner (1986), who uses a cultural-hermeneutic interpretation of Wittgenstein to emphasize how technologies are always embedded in forms of life. Another exception is Nordmann (2002), who has used the Tractatus to link Wittgenstein with thinking about technology. Furthermore, Hans Poser has discussed forms of life in context of technical design research, but without a concrete Wittgenstein exegesis (Poser 2004). There are also some references to Wittgenstein in the context of AI research (Birnbacher 1995; Friesen and Berr 2004: 237-239). Bernhard Irrgang cites Thomas Rentsch's interpretation of Wittgenstein and Heidegger (Rentsch 2003) as one conceptual fundamental of technical practice (Irrgang 2007: 89-98). Kogge (2015) proposes a "grammatical" investigation of technology, which aims at clarifying concepts used in philosophy of technology in a way that reveals distinctions relevant to our life-reality as they structure our actions and experience. For instance, Wittgenstein's concept of "family resemblances" can be used in this way. However, this approach is still mainly linguistic/conceptually oriented, whereas we-in line with the empirical turn-emphasize also the materiality of tools and concrete embodied techniques and add a transcendental argument. We agree with Peter Keicher, who claims that Wittgenstein's works can be interpreted both as a philosophical approach of technology and as technical praxis of philosophy itself (2008: 193). These are all interesting suggestions, but there is much more work to be done. The exceptions confirm the rule: there is very little attention to Wittgenstein in contemporary philosophy of technology, and a systematic interpretation and use of Wittgenstein for philosophy of technology is lacking.

At the same time, in Wittgenstein scholarship there has been little attention to technology. While it is often acknowledged that Wittgenstein was also working as engineer and architect, links between these biographical elements and his work remain undertheorized and are discussed in a way that does not render them interesting for philosophers of technology. An exception is Sterrett (2005), who links Wittgenstein's thinking to aeronautical research, in particular the building of experimental models. This is interesting, since a connection is made between 
technology and Wittgenstein's thinking. More generally, if we take a closer look at Wittgenstein's work we see that several conceptual traces of engineering can be found: the Tractatus, but especially his later works after 1930, bear explicit references to tool use and techniques, also in relation to his method (Nordmann 2002: 358-368; Keicher 2008: 191; Kogge: 95). One example can be found immediately at the beginning of the Philosophical Investigations:

A is building with building stones: there are blocks, pillars, slabs and beams. B has to pass him the stones and to do so in the order in which A needs them. For this purpose they make use of a language consisting of the words "block," "pillar," "slab," "beam". A calls them out; B brings the stone which he has learnt to bring at such-and-such a call.-Conceive of this as a complete primitive language. (Wittgenstein 2009: § 2/6e)

This reference to building and technology is not an incidental hint. Wittgenstein uses it as a paradigmatic case for his further elaborations, for example explicitly in $\S$ 6 (2009: $\S 6 / 7$ e), $\S 19$ (2009: $\S 19 / 11$ e) or $\S 48$ (2009: $\$ 48 / 27$ e) and in On Certainty $\S$ 566 (Wittgenstein 1969: §566/74e). Our paper addresses these gaps and this twofold "forgetting" (philosophers of technology forgetting Wittgenstein and Wittgenstein scholars forgetting technology) by taking significant steps towards constructing a systematic framework for a Wittgensteinian philosophy of technology.

While we acknowledge that there is continuity between the Tractatus and his later writings (Rentsch 2003: 340ff.), in this paper we are focusing primarily the later work, especially the Investigations. We choose the Investigations because this work is highly traversed by many explicit examples of technical practice, but also by a lot of methodological claims that are not only relevant to philosophy of technology but have also broader implications. In addition, we will also refer to $\mathrm{On}$ Certainty when we use Wittgenstein's epistemology. This should serve as a starting point for further more detailed research on Wittgenstein as a philosopher of technology. Our paper itself can be seen as performance and use. This is why we include the dramatic indications "Act" and "Scene" to label the headlines and sub headlines. In our philosophical "performance" we use Wittgenstein's philosophy of language and his epistemology, and twist and interpret them in a way that delivers an interesting understanding of technology. This reflects Wittgenstein's own understanding of doing philosophy: he did not so much present "arguments" but was rather performing philosophy. The aphoristic form of his Investigations and other writings illustrates that philosophy cannot be put in a theoretical form; instead it is a reflexive performance-not amounting to postmodern relativism, but rather relational rehearsals motivated by critical rational thinking and aware of the limits of rational thinking. As Friedrich Kambartel argued, these exercises should lead to philosophical changes of perspectives, which show a way the reader practically needs to go, but are not replaceable by a looking at a map only (1989: 158).

In our first act we perform a perspective on Wittgenstein's philosophy of language as articulated with the terms language use, language games, philosophical grammar and forms of life in the Investigations, and read into them a first set of building blocks for a philosophy of technology. In particular, we draw on the analogy Wittgenstein makes between language use and tool use. We further develop and extend this analogy 
to arrive at a view of technology use (technique) that is performative and that is embedded in games and forms of life. This interpretation, which is more systematic than that of Winner and integrates in an original way the language use/tool use analogy, is then connected to the cultural and hermeneutic interpretations of Wittgenstein that have been made in relation to his philosophy of language.

We follow a similar procedure when we turn to Wittgenstein's methodology in the Philosophical Investigations and On Certainty in order to first articulate his epistemology and discuss how we can use it to better understand technology. We show that Wittgenstein responds to Cartesian dualistic thinking by developing a deep critique of modern philosophy. Here we emphasize embodiment, know-how, and implicit knowledge, and then apply this to knowledge in technology use and technology performance, which, so we argue, is always part of a technological practice, takes place in concrete situations, involved implicit knowledge and knowhow, is holistic, and is embodied.

In the last part of the paper we take a transcendental turn: based on a conception of philosophical grammar (in contrast to grammar as syntax), we interpret games, forms of life, and grammar as transcendental conditions that make possible and structure embodied use, technique, and performance. We place our use of the concept of the transcendental in a Kantian trajectory, but give it a different and more radical and practical meaning than Kant by including ordinary language, philosophical grammar and forms of life. In addition (and this makes up the radicality of our paper with regard to Wittgenstein scholarship), we argue that if we understand language as a technology, Wittgenstein's theory of language use can be integrated within a larger theory of technology use and performance, interpreted in a transcendental way. This move turns Wittgenstein into a (use and performance oriented) philosopher of technology, albeit one who focused on language. In our conclusion, we indicate some avenues for further research in this direction and point to other aspects that need further attention such as the issue of time/finitude and technology.

\section{Use, Games, and Forms of Life: Wittgenstein's Philosophy of Language and the Performative View of Technology Use as Tool Use that Emerges from it (Act 2)}

\section{Wittgenstein's Concepts of Language Use, Language Games, and Forms of Life Applied to Technology (Act 2, Scene 1)}

Wittgenstein's view of language use in the Investigations can be summarized as follows. For Wittgenstein meaning is not tied to a particular word, but instead depends on use. It is not "an aura the word brings along with it and retains in every kind of use" (2009: §117/53e) but it is use that gives a sign its meaning, it's "life" (2009: §432/ $135 \mathrm{e})$. Moreover, this use is not stand-alone but depends on a larger social and cultural context of use, which Wittgenstein calls "language games" and "forms of life":

I shall also call the whole, consisting of language and the activities into which it is woven, a "language-game". (2009: $\$ 7 / 8 \mathrm{e})$ 
When we use language, we follow certain rules. We play a game. When we learn to use language, we learn these rules. But they are often not explicit. We learn by watching and by participating in a game, as when we learn a board game (2009: §31/18e-19e). Learning a language, then, is like learning a skill and hence it also involves implicit knowledge (see also the next part of the paper). But there are already rules and skills that are given, and there are others who have played the game before. When we speak, there is already a language, which has been used by others before us, and which is linked to a broader context. Learning of particular games always has a social and cultural context, of which language games are part. Wittgenstein calls this a 'form of life': "to imagine a language means to imagine a form of life." (2009: §19/11e) This view implies that meaning depends on language use, and this language use is an activity and a game, which is part of a larger cultural whole - a form of life. To show that 'the speaking of language is part of an activity, or of a form of life', Wittgenstein mentions a number of activities such as giving orders, drawing, reporting, etc. (2009: $\$ 24 / 15 \mathrm{e}$ ). The point is that meaning is tied to these (social) activities; it is not attached to a particular sign. There is a larger whole, a form of life-later in this paper these will be discussed as transcendental grammars.

Wittgenstein's primary view is a view of language. Yet indirectly, Wittgenstein also says something about technology. In the Investigations, he makes an interesting analogy between use of language and use of tools. To make his central point about meaning being tied to language use, Wittgenstein compares the use of language to the use of devices and instruments. He writes: "to invent a language could mean to invent a device for a particular purpose" (2009: §492/145e) and "Language is an instrument. Its concepts are instruments”. (2009: §569/159e). He even explicitly mentions tools:

Think of the tools in a toolbox: there is a hammer, pliers, a saw, a screwdriver, a rule, a glue-pot, glue, nails and screws.-The functions of words are as diverse as the functions of these objects. (And in both cases there are similarities.) (2009: §11/9e)

This analogy is usually overlooked by interpreters of Wittgenstein and philosophers of technology, but gives us an interesting link to thinking about technology. It suggests that language is a technology, and-if we apply Wittgenstein's view of language use to technology - that the use of tools is also part of language games and part of a form of life. In other words, we can turn the metaphor around: the use of tools resembles the use of words.

Our interpretation of Wittgenstein's view of language is in line with more "cultural" interpretations of Wittgenstein (e.g., Winch 1958), which stress that our use of language is embedded in social behaviour, rules, and cultures. Moreover, our reading of Wittgenstein in terms of technology is also compatible with Langdon Winner's, who already suggested that technologies are part of a form of life in the sense that they are "woven into the texture of everyday existence" (Winner 1986: 12) and that life would be unthinkable without them. Our world becomes one with that of technology. Technology cannot be "turned off" (1986: 12). Moreover, Winner stresses that there is a given. Current technological changes are variations of 
older patterns (1986: 12f.) and hence “Wittgenstein's philosophically conservative maxim 'What has to be accepted, the given, is-so one could say-forms of life' could well be the guiding rule of a phenomenology of technical practice" (1986: 13). For instance, the language games we play between humans such as meeting someone or asking a question and awaiting an answer (saying "Hello," etc.) also shape our use of computers (1986: 13f.). Winner writes about the computers of the 1980s but what he says could also be applicable to contemporary social robots:

Forms of life that we mastered before the coming of the computer shape our expectations as we begin to use the instrument. (...) We carry with us highly structured anticipations about entities that appear to participate, if only minimally, in forms of life and associated language games that are parts of human culture. (1986: 14)

Thus, when we use technologies, this use is always embedded in activities and patterns that were there before the technology enters our lives. We endorse this view, but in our reading firmly anchor it in the analogy Wittgenstein makes between language use and technology use (understood as tool use): the relation between technology use and forms of life is structurally similar to the relation Wittgenstein sees between language use and forms of life. When we use language and technology, there is already a language and there are already technologies, and there are already activities and cultural forms available that shape and structure these uses of language and technologies.

\section{Technology Use, Games, and Forms of Life: A Performative View of Technology Use as Tool Use (Act 2, Scene 2)}

Another way of making this point and apply Wittgenstein's remarks on language and tool use to thinking about technology in general is to use the concept of 'performance'. Both Wittgenstein's substantial points about language and his very methodology in the Investigations and other writings can be interpreted as centring on performance, understood as meaningful and successful practice-whether linguistic or technological. Even philosophy, understood as language use, becomes a performance: "We go towards the thing we mean" (Wittgenstein 2009: §455/140e). History of language, and hence history of thinking, is then a history of performances, which have left material traces. Wittgenstein used the example of an old city:

Our language can be regarded as an ancient city: a maze of little streets and squares, of old and new houses, of houses with extensions from various periods, and all this surrounded by a multitude of new suburbs with straight and regular streets and uniform houses. (Wittgenstein 2009: $§ 18 / 11$ e)

In his later work, Wittgenstein was interested in understanding why some actions end successful and include meaning while others lack any sense at all. His use of the concepts language games and form of life, but also his epistemology focused on technique (see below), can be seen as an answer to that question: performances are meaningful and successful if they are forms of skilled engagement and if these 
forms are embedded in larger wholes, grammars, which constitute a kind of "given" that is usually not doubted. Performance therefore includes a pragmatic meaning criterion; grasping the meaning is a matter of trial and error.

One cannot guess how a word functions. One has to look at its application and learn from that. (Wittgenstein 2009: § 340/116e)

Now the metaphor of performance can also be used to highlight the social and cultural aspects of technology use. If "individual" technology use and technology performances are always embedded in games and a form of life, then a phenomenology and hermeneutics of technology should not only focus on how individual subjects relate to the world via technology, but should also take into account how this very relation and this use of technology is structured by games and a form of life. Success and meaningfulness of use is socially defined. When we perform, the success of this performance crucially depends on others, in particular on the meaning others (spectators and co-performers) give to what we do. And those others can only give meaning to our performance, if this performance is embedded in known activities, games, and other, larger social-cultural structures-a form of life. The meaning and success of the performance, then, depends on this link with patterns we already know. An alien observer, so to speak, could not make sense of what we do. Our actions would not even count as a performance. For meaning to arise and for the performance to be successful, observer (and co-performer) and performer must have a shared understanding about what the activity and the game are about; ultimately, they it must be presupposed that they share a form of life, which makes possible that the performance can be meaningful and successful.

This is also applicable to performance with technology. Our performance with technology only makes sense if we already know activities and games, and a form of life. This knowledge must be presupposed for the technological-performative and technological-communicative act to make sense at all, and is also a necessary condition for its success. One may object that technologies have functions, which are rooted in their materiality. This is correct. But the function itself would not make sense, indeed would not count as a function at all, in isolation from a social and cultural context. For instance, the function of a word processor is to produce a text. We perform with it in order to produce a text. Another way of saying this, is that to produce a text is the word processor's function. But the production of a text is only meaningful if it is related to known activities such as writing and reading, rules such as grammatical rules, games such as writing an academic article, and a form of life that is pervaded by a written culture and a (particular) language, which shape and make possible our writing. In a culture that knew no writing (but has a culture of orality, for instance), our word processing performance (as an activity of writing, as a writing performance) would not make sense, and would not be successful; the device and our use of it would hence be dysfunctional. And if we were to write in English in a social environment in which no-one understood English, then our performance would also lose at least some of its functionality, if not all. Of course one could observe the behavior of, say, a foreign tribe one does not know, and use this to make sense of the language they use. But in order to give meaning to the behavior, there needs to be shared behavior and, related to that, shared meaning and 
shared culture. Wittgenstein writes: "Shared human behaviour is the system of reference by means of which we interpret an unknown language" (Wittgenstein 2009, § 206: 88e). Thus, using a technology, understood as performance, presupposes a lot of knowledge, which is social knowledge in the sense that it is shared, and which may often be implicit, but which must be presupposed in order to guarantee success. Use of technologies thus depends on all kinds of knowledge.

But what does this "knowing" consist in? The previous argument shows that we do not only need "operating" knowledge (knowing how to "technically" operate the device in a narrow sense, as in "knowing how" to produce letters on a screen) but performative knowledge in a broader sense, encompassing a lot of other knowledge we usually do not think about when we use a device, but which must be presupposed (e.g., knowing how to write, which presupposes language). But how is this wider knowledge related to operating skill? And where is the material and the body so far in what may seem a "cultural" interpretation (falsely understood as opposed to the material and the bodily)? In order to arrive at a more complete view of use of technology understood as performance, we need to pay more attention to embodiment and skill, and more generally to technology as technique and skillrather than as artefact we use. This can be done by again using Wittgenstein, in particular by interpreting his epistemology.

\section{Embodied Know-How in Technology as Technique: Wittgenstein's Epistemology and Its Implications for Technology Use and Performance (Act 3)}

\section{Embodiment, Situated Knowledge, Implicit Knowledge and Know-How in Technology Use as Technique: Wittgenstein's Epistemology (Act 3, Scene 1)}

Let us connect the view of technology as tool use to thinking about technique and skill. In philosophy in general and also in philosophy of technology there has been some work on skill. For instance, Polanyi (1958) has famously argued that implicit knowledge serves as basis for scientific research in contrast to explicit knowledge. Capabilities which we are not able to tell (make explicit) play major roles in epistemic human-world relations and include perceptions as well as the usage of probes and laboratory tools. In the context of critical controversies about AI technologies, Dreyfus (1972) emphasized the epistemic role and significance of human bodies and skills: bodily skills serve as a basis for human cognition. Intelligence is not only a matter of formal calculation; it includes also tacit competences, which serve as general conceptual features of a philosophical approach to technology (Coeckelbergh 2012: 135f.; Irrgang 2001). Ihde (1979) also interprets technology as practice, not as static artefact. In his understanding of technological practice, competences in using tools also play a role. In current cognitive sciences the enactive approach became an influential research paradigm, including bodily capacities, skills and body extensions by tools as well (Varela et al. 1997; Noë 2004). There are also many other views in phenomenology/ 
hermeneutics, pragmatism or cognitive science that focus on embodiment and skilled engagement in cognition. Now this approach is applicable to technology use. Music is a concrete example (Funk and Coeckelbergh 2013; Funk 2015) and we will soon say more about music as a technological practice. Let us first turn again to Wittgenstein's later work in order to link the Wittgensteinian view of technology developed in the previous section to Wittgenstein's epistemology, in a way that tells us more about technique and skill.

In the Investigations, Wittgenstein already says that using and learning a language is about mastery, and suggests that this involves implicit knowledge (see also Funk 2010). Consider again what Wittgenstein says about board-games:

one can also imagine someone's having learnt the game without ever learning or formulating rules. He might have learned quite simple board-games first, by watching, and have progressed to more and more complicated ones. [...] he has already mastered the game. (Wittgenstein 2009: $\S 31 / 18 \mathrm{e}, 19 \mathrm{e}$ )

This remark is entirely in line with the previously cited works on skill, tacit knowledge, technique, and performative knowledge. Mastery of a game can only be reached if one has this kind of knowledge. Moreover, in Wittgenstein we also find explicit references to mastery as technique:

The grammar of the word "know" is evidently closely related to the grammar of the words "can," "is able to". But also closely related to that of the word "understand" (To have 'mastered' a technique.). (Wittgenstein 2009: § $150 / 65 e)$

And:

To understand a sentence means to understand a language. To understand a language means to have mastered a technique. (Wittgenstein 2009: § 199/87e)

If we apply this view to technology, then one could re-conceptualize technology use not only as performance but also as technique, which requires the adequate knowhow and skill. We agree with Werner Kogge's claim that Wittgenstein talks about technology in the context of procedures and (also intellectual) competences (2015: 101-103). But the tacit dimension of knowledge is also emphasized by Wittgenstein, who distinguishes between several forms of knowledge:

Compare knowing and saying:

how many metres high Mont Blanc is

how the word "game" is used

how a clarinet sounds.

Someone who is surprised that one can know something and not be able to say it is perhaps thinking of a case like the first. Certainly not of one like the third. (Wittgenstein 2009: § 78/41e)

Here Wittgenstein's view is very close to Michael Polanyi's, in particular his famous slogan: "we can know more than we can tell" (Polanyi 2009: 4). In On Certainty, a mix of Wittgenstein's very last writings, Wittgenstein also compares learning language to the learning of a skill: "We say: if a child has mastered 
language - and hence its application-it must know the meaning of words" (Wittgenstein 1969: $§ 522 / 68 \mathrm{e}$ ). He stresses practical knowledge:

If, however, there are several ways of finding something out for sure, like counting, weighing, measuring the stack, then the statement "I know" can take the place of mentioning how I know. [...] But here there isn't yet any question of any "knowledge' that this is called "a slab," this "a pillar," etc. (Wittgenstein 1969: § 565, § 566/74e)

Instead of certain knowledge, in the sense of something that has been measured, we have tacit knowledge about concrete sounds and how to sensory perform it. We infer that using words presupposes some explicit knowledge (explicit rules) but also implicit knowledge: knowledge acquired by watching (listening) and participating in language games, by growing up in a particular form of life. But we also acquire knowledge by means of material performances. Applied to technology, Wittgenstein's view implies that using technology is embedded in a game in a sense that for using the technology one has to perform with it, learn a particular game (e.g., playing a musical instrument etc.), and grow up in a particular cultural context (e.g., a musical family).

On Certainty is also relevant here since it includes an intellectually deep contention about skepticism and the possibilities of knowledge as such, which we can use to elaborate the epistemology of technology as technique. Wittgenstein criticized the static ontology of Cartesian dualism and indeed its dualism itself. He wanted to understand knowledge not as an inner mental state but as practical process, which is immune against skeptical intervention. His point about the impact of tacit knowledge and his counterargument against skepticism goes beyond the cogito-argument (I think therefore I am) as found in Descartes. Instead it focuses on the success of practice, which is also a social matter. I can have success or failure when playing with tools, language, values or ideologies-and this is a matter of what we are and do. The concrete person is always socially embedded. (Subjectivity is hence understood as intersubjectivity and trans subjectivity.) For technology this means that technology use is also about success in a social sense, not only in a "technical" sense in the usual, narrow sense of the word. Technology is not only about how we relate to the world as individuals, but has consequences for the social and intersubjective. This point can also be put in the language of "games" and "form of life": a game and a form of life gives us a certain "grammar" for the successful use of technology. (We will return to this point in the fourth section.)

To this social approach we can add the aspect of development. Consider again Wittgenstein's view of language, which can be interpreted in a developmental way. Perhaps in the beginning children or other new language users need instructionthey need to hear a particular word and connect this with a particular meaning-but as they get better language users, and indeed if they want to become better language users, they need to learn in a more implicit way and get themselves embedded in an entire form of life (By the way, this Wittgensteinian point also shows why it is so difficult for computers to translate language; algorithms and databases work with explicit knowledge, whereas human language involves an implicit knowledge that can only be learned as one learns language games within a specific cultural context). 
Similarly, technology can be conceptualized as technique and performance that requires the development of implicit knowledge.

Moreover, we must add the dimension of embodiment, which can be further developed by elaborating Wittgenstein's critique of Cartesian premises. His later works are not only traversed by critical thoughts that reject a naive Cartesian dualism (Gier 1981: 13; Rentsch 2003, thesis 3 \& 4: 15, 287ff.) in favor of a more social and cultural approach; we can also read Wittgenstein as replacing the postulate of Cartesian res cogitans - the process of non-physical and pure inner cognition-by a critical proposal of bodily and socially embedded practice. Linguistic meaning is no matter of isolated inner cognition, but of sensory practice:

Misleading parallel: a cry, an expression of a pain-a sentence, an expression of a thought. As if the purpose of a sentence were to convey to one person how it is with another: only, so to speak, in his thinking apparatus, and not in his stomach. (Wittgenstein 2009: § 317/111e)

Cognition and thinking do not belong to an ontologically separated substance, as Descartes at least suggested with his argument in the Meditations; instead, in performance, body and mind are together. This also means that language and thinking are innately linked to the body, are deeply embodied, at the level of performance:

Thinking is not an incorporeal process which lends life and sense to speaking, and which it would be possible to detach from speaking [...]. (Wittgenstein 2009: $§ 339 / 116$ e, see also $§ 454 / 140$ e et passim)

Indeed, in the Investigations, Wittgenstein constantly questions the inner-outer distinction. For example, he writes that "The arrow points only in the application that a living creature makes of it. This pointing is not a hocus-pocus that can be performed only by the mind" (Wittgenstein 2009: $§$ 454/140e) and that "An "inner process' stands in need of outward criteria" (Wittgenstein 2009: §580/161e). Moreover, concrete performances depend on concrete situations, both in everyday life and in methodological reconstructions: "An expectation is embedded in a situation, from which it arises" (Wittgenstein 2009: §581/161e). Now this thought can be connected with technique and embodiment. Techniques can be seen as the concrete bodily skills (which we may call "innate technique") of using tools, which enable successful handling of contingent situations. Tool use plays a crucial role here: not only as external physical artifact, but also in another sense: tool use already starts with usage of the own human body and its capacities.

Thus, one could say that Wittgenstein raises the same question as René Descartes did three hundred years earlier: How to find a solid ground of reasoning in contention with skepticism and the possibility of radical disbelief? Descartes' answer-I think, therefore I am-was to postulate two separated ontological substances: pure cognition (res cogitans) and physical bodies with spatial extension (res extensa). Wittgenstein's answer differs. In what we take to be a somewhat Feuerbachian manner (Feuerbach 1983: e.g., § 36/91), Wittgenstein's solution can be translated into the slogan: we perform, therefore we are. This also means that 
there is an epistemological basis, not in an abstract "I", but in a shared language, and in technique and performance. In On Certainty he writes:

That is to say, the question that we raise and our doubts depend on the fact that some propositions are exempt from doubt, are as it were like hinges on which those turn. (Wittgenstein 1969: § 341/44e)

Some propositions or sentences ("Sätze") "are exempt from doubt". The technical metaphor Wittgenstein uses ("are as it were like hinges on which those turn") illustrates the sensory postulate behind his contra skeptical argument.

If I want the door to turn, the hinges must stay put. (Wittgenstein 1969: $\S$ $343 / 44 \mathrm{e})$

We can interpret this hinges example as saying something about technology use: for Wittgenstein the use of an artefact is not an isolated inner cognition, but a finite bodily practice, which can succeed or fail in concrete socially shared situations. These practices, performances, and techniques are thus revealed as a solid ground of reasoning, as something that is presupposed when we reason and which we accept and trust, without having explicit knowledge of it and without having certainty. With pragmatic modesty Wittgenstein says:

My life consists in my being content to accept many things. (Wittgenstein 1969: § 344/44e)

And:

And substantiation comes to an end. (Wittgenstein 1969: $§ 563 / 74 \mathrm{e}$ )

One could say that Wittgenstein re-pragmatises the Cartesian argument. Both agree that something like a transcendental process (see below) serves as condition of possibility of skepticism and radical doubts. Our acceptance of many things makes possible our doubt in the first place. But in contrast to Descartes, Wittgenstein locates this transcendental ground and process not in an ontologically separated sphere of pure cognition, but in praxis. Everyday life practice and performance in all its manifold bodily and sensory potentials serves (a) as condition of possibility of skepticism as such, and (b) as axiom or transcendental ground (or condition of possibility) of any form of knowledge and scientific research:

That is to say, it belongs to the logic of our scientific investigations that certain things are in deed not doubted. (Wittgenstein 1969: § 342/44e)

Certain things ("Gewisses") are not doubted in deed ("in der Tat"). "In deed" means in concrete practice and performance. Having doubts is itself a process or practice. Descartes attends to this doubting. But in contrast to Descartes, Wittgenstein has a sensory and bodily technical understanding of this process. For scientific research, for instance, this means that there is also trust in the technology used:

If I make an experiment I do not doubt the existence of the apparatus before my eyes. (Wittgenstein 1969: $§ 337 / 43$ e) 
The apparatus - the technology as tool and device, or as the assemblage of tools and devices-here points to science as a technological practice which enables experimentation. In a modern understanding of experimental sciences, which today also include performances in high tech laboratories and computer models, this technological embedding of succeeding or failing experiments serves as a solid ground and process for methodological reasoning. It is not the logical sentence or natural law as such.

Our talk gets its meaning from the rest of our proceedings. (Wittgenstein 1969:

$\S 229 / 30$ e)

It is precisely this counter-skeptical movement in combination with the classical Wittgensteinian argument about language (linguistic meaning is generated in practice) that enables not only conceptual links between philosophy of language and philosophy of technology, but also bears methodological potentials for philosophy of technology as discipline. We already used the term "conditions of possibility" here; in the last part of this paper, we will further develop this argument as a transcendental argument. But let us first further show the implications of this epistemological analysis for thinking about technology.

\section{Embodiment, Situated Knowledge, Implicit Knowledge and Know-How in Technology Use/Performance as Technique: Implications for Thinking about Technology (Act 3, Scene 2)}

What does it mean to say that technology, understood as technique and technological practice (and not only as artefact or "thing"), involves the kind of implicit, embodied knowledge and skill Wittgenstein wrote about? Learning to use technology requires learning a skill. Perhaps we need instruction in the beginning, but as we gain mastery, we have more implicit knowledge, know-how, which is in turn embedded in games and forms of life. The latter cannot be made entirely explicit but "live" in the socially shared know-how and performance.

Let us offer the example of music to explain this. Music is a form of life and involves more than only adding some isolated techniques or handbook knowledge to an already existing game of life. Learning music includes a broad range of trainings: body movements, harmonic theories, scores, very material perceptions, finger styles or aural training. Social aspects also play a crucial role. Often music is embedded in common, transsubjective performances in rehearsal rooms, studios, stages etc. Skills are shared and succeeding ways of talking about those skills are shared as well. Music is always more than scores and it is embedded in a grammar which is more than harmonic theory. Aural training changes sensory skills such as finger training. At the same time perceptions changes, we feel, hear or see more things or at least in a different way. And this can succeed or fail. Not the score serves as a truth and meaning criterion here, but the performance and the way of life which includes adoptions of how to interpret the score in a succeeding performance. Succeeding repetition, for instance in many training sessions, is the basis of implicit knowledge. No-one can become a musician without practice and rehearsal (And beginners need instruction). Moreover, even if music is not literally performed with others, music as 
technique is embedded within a larger form of life, which includes patterns and culture that shape the practice, for instance rock music-culture.

Some references to Wittgenstein and technology can be found in philosophy and social sciences ${ }^{1}$ of music, especially when musical instruments are analyzed and not only scores with a theoretical or historical interest. For example, Trevor Pinch uses Wittgenstein in order explain how applicability in several user situations challenged the design process of early Moog synthesizers and their transformation into keyboards: "Just as Wittgenstein famously argued that the meaning of language comes from use-so too the meaning of musical instruments is to be found in their use" (Pinch 2006: 58). In another study Pinch and Trocco argue:

Wittgenstein famously argued that the way to understand language is from its use. Similarly, the way to understand musical instruments is not from their essences-what their theoretical possibilities are-but from the way people who actually make the music put them into practice. (Pinch and Trocco 2004: 10)

We propose to generalize this claim to technology use in general: we can only understand technologies in and from their use, that is, in technological practice, which is also culture-in-practice.

This use orientation also enables us to point to the link between the materiality of technologies and cultures of use. Artefacts in use are material carriers of forms of life. If they do not fit into or further develop an already existing set of practices, technological innovations will fail. Innovation, technological use and success, and material embedding of cultural habits belong together. Again Moog synthesizers are examples for that. They have been successful partly because of their material embodiment: their materiel representation/embodiment of Classical music as the keyboard follows exactly the geometry of black and white keys as it can also be found in usual pianos. Similar to typewriters and computer keyboards (David 1985) synthesizers and pianos are linked by a material developmental path: the keyboard as constant user interface that enables successful innovations fitting into already established forms of life.

In his study of Listening and Voice, Don Ihde also sees musical technologies as practice in concrete cultural situations. He refers to Wittgenstein when he describes

\footnotetext{
1 There is a diverse and multifaceted discussion about Wittgenstein in more empirical contexts of sociology and STS studies. Our paper follows a primary philosophical interest. But at this point we also want to acknowledge that our claims regarding technologies and forms of life, social aspects of knowledge, tool use and tacit knowledge are compatible to several other approaches in the social sciences that use Wittgenstein to understand scientific practices and knowledge production. Consider for example Steven Shapins and Simon Schaffers's influential Leviathan and the Air-Pump: Hobbes, Boyle, and the Experimental Life $(1985$, e.g.,: 15, 51) which uses the notion of 'form of life' to talk about the technology of the airpump, or David Bloor's Wittgenstein: A Social Theory of Knowledge (1983) and Wittgenstein, Rules and Institutions (1997). And for instance Collins (1974) has done work on how tacit knowledge plays a role in science (see also the special issue by Soler and Zwart 2013). Michael Lynch has also used and discussed Wittgenstein in his work, for instance the use of rules in Scientific Practice and Ordinary Action (1993; see also 1997). Due to reasons of space we cannot go into the details at this point. But it could be a fruitful future work to combine our philosophical claims about Wittgenstein and technologies with those more empirically oriented works.
} 
the ways in which philosophers and artists discern different possibilities and variations in relation to the phenomena:

There is a sense in which Wittgenstein in particular was sensitive to such nuances of differences in a very "phenomenological" way. The notion of family resemblances [...] is an attempt to recognize the noncommon relatedness of many phenomena in the mesh of ordinary language that does not display simply some clear "logical" structure. (Ihde 2007: 33f.)

This remark on language takes us back to the insights of the first part of this paper. For philosophy of technology, this Wittgensteinian approach means that part of its central tasks must be the hermeneutic work of relating particular uses of technology to activities, games, and larger social-cultural wholes, forms of life-which include material aspects as well. If we must put this in dualistic terms at all: the "material" must be related to the "cultural". This approach does not mean that we must give up an interest in the material aspects of technologies, in 'things', but rather that we must relate the particular use of particular things, including their material aspects, to activities and games, and more generally to a social and cultural context. Understanding technology, then, means understanding a form of life, and this includes technique and the use of all kinds of tools-linguistic, material, and others. Then the main question for a Wittgensteinian philosophy of technology applied to technology development and innovation is: what will the future forms of life, including new technological developments, look like, and how might this form of life be related to historical and contemporary forms of live? Moreover, we can merge this Wittgensteinian question and approach with a more pro-active approach, which is increasingly popular in contemporary philosophy of technology and largely constructed in response to Heidegger rather than Wittgenstein (starting, e.g., with Dreyfus 1972; Ihde 1979): can we re-design, develop new, technologies that lead to a kind of form of life we think is valuable and meaningful for humans? This development includes trial and error: we can perform more sentences and perform more technical actions, than those, which we would call "meaningful" or associate with a succeeding technical move. Furthermore, others also perform, make moves, use words, and so on. The interesting question is then how to respond to others, for instance: how do we learn to enfold/bear out of ourselves a point of view, which links our personal linguistic and technical potentials to the many sometimes strange and interesting, sometimes trivial things performed by other persons? The question how to relate to technology then means: how do we relate to the games and form of life in which we perform and live? How is success in human life possible? What are the conditions of possibility? This question leads us to a transcendental argument, which recognizes that we are always carried by a form of life, which makes possible technological and other uses and performances, and which cannot easily be changed. 


\section{A Transcendental Interpretation (Act 4)}

Let us now further support and re-formulate our interpretations and arguments in the preceding parts of the paper by taking an explicit transcendental turn, albeit giving "transcendental" a specific meaning which differs from, say, Kant or Husserl. This move will also enable us to further elaborate what we take to be Wittgenstein's approach to philosophy and its implications for doing philosophy of technology.

\section{A Transcendental Turn (Act 4, Scene 1)}

In the preceding part, we have been focusing shared social and bodily processes in succeeding situations as a pragmatic ground against skepticism. We also linked this back to the first part of the paper, stressing that our performances with technology are always embedded and constrained by a form of life. In these performances, we already touched upon the transcendental argument (we mentioned conditions of possibility), but this needs to be further elaborated in this section. In order to make this transcendental turn, let us begin with the concept of "process". What does process mean? Process is a matter of practice and has something to do with time. And it is the question of time in Augustine's Confessions that gets Wittgensteins started in the Investigations:

Augustine: "What, then, is time? If no one asks me, I know what it is. If I wish to explain it to him who asks me, I do not know" (Augustine 1955: 162 [Conf. XI 14]).

Wittgenstein's response to this is not only to point to the use of words, as we already indicated earlier in this paper, but also to stress implicit knowledge again and to suggest a paradox:

Not, however, as if to this end we had to hunt out new facts; it is, rather, essential to our investigation that we do not seek to learn anything new by it. We want to understand something that is already in plain view. For this is what we seem in some sense not to understand. Augustine says in Confessions XI. 14, "quid est ergo tempus? si nemo ex me quaerat scio; si quaerenti explicare velim, nescio".- - This could not be said about a question of natural science ("What is the specific gravity of hydrogen?", for instance). Something that one knows when nobody asks one, but no longer knows when one is asked to explain it, is something that has to be called to mind. (And it is obviously something which, for some reason, it is difficult to call to mind.) (Wittgenstein 2009: $§ 89 / 47$ e)

It is hard to call this 'something that one knows when nobody asks one, but no longer knows when one is asked to explain it' into mind, because it is not the opposite of the mind. Any opposite or strong difference can turn more easily into epistemic focus, because of a strong distinction (contrast). But here we are not confronted with a strong distinction. What we find in this investigation is a transcendental condition of possibility of the process: we try to call to mind, but we 
can only relate what is already related (Rentsch 2003, thesis 6: 16; Coeckelbergh 2012: 138). The paradox is: we do not know but we already know.

In order to systematically elaborate a philosophical solution of this paradox, we propose to interpret Wittgenstein and our own interpretations and argument offered in this paper in a transcendental way. In the process, we further develop existing interpretations of Wittgenstein that focus a transcendental argument (Gier 1980: 257; Gier 1990: 280, 285; Rentsch 2003: 291ff., 340ff.; Benton 2002: 155; Coeckelbergh 2012: 133-138) but use, enhance and elaborate them in order to offer new methodological impulses for the philosophy of technology.

One of Wittgensteins statements directly suggests a transcendental interpretation of his views:

yet our investigation is directed not towards phenomena, but rather, as one might say, towards the 'possibilities' of phenomena. [...] Our inquiry is therefore a grammatical one. (Wittgenstein 2009: § 90/47e)

The crucial words here are not only "possibilities" (transcendental approaches focus on conditions of possibility) but also "grammar". Let us try to understand Wittgenstein's concept of a philosophical grammar-also called existential grammar (Rentsch 2003: 417ff.) -in order to understand how Wittgenstein transforms the Kantian notion of transcendental.

Wittgenstein is not a postmodern philosopher. He is deeply rooted in modern thinking by radically emphasizing scientific enlightenment and critique of reason ("Vernunftkritik") in the tradition of Immanuel Kant (Kambartel 1989: 148-150). In a Kantian manner, Wittgenstein argues for a categorical difference between situation invariant and situation variant sentences. But more than Kant, Wittgenstein was focusing on language practice. Language practice of sciences-natural but also social science or engineering sciences - are shaped by situation invariant ways of using language. Sentences, hypotheses or natural laws are intended to be valid at any time in any place. Therefore, those practices of talking are independent from the concrete situation in which the sentence is practically performed. On the other hand, everyday life language is - to put it into 21 st century terms - multistable. Words are multistable, for example the word "mouse". It could refer to a computer input device or to a specific mammal. The same happens with the tool computer mouse. Its application is open to abuse many variations: for gaming, design, social interaction in social media, or as weapon in cyberwar. In the philosophy of technology, Ihde often refers to this concept. In his very few Wittgenstein references, he mentions Thomas Kuhn and the duck-rabbit picture (gestalt shifts), which looks like a duck and a rabbit at the same time (Ihde 1991: 14-16; Ihde 2006: 288). For our purposes, it is important to highlight the conceptual parallel between the multistability of technologies and language, and its innate links: the word "mouse" received an additional meaning after personal computers and pursuant software became aspects of new situations of performances. Apparently different meanings (gestalts) are possible, and technology makes possible different meanings.

This insight brings us back to Wittgensteins claim about grammar. The innate grammar of ordinary language is specialized to practically handle manifold contingent circumstances. Whereas scientific language enfolds its meaning in very 
peculiar scientific situations, everyday life language is embedded in multiple possibilities of genuine human actions (Kambartel 1989: 155-158). Linguistic actions shape practical forms of human life, and our use of language is made possible by a form of life. Whereas Kant used the more legal term "constitution," Wittgenstein introduced the linguistic term "grammar" in order to conceptualize this (Kambartel 1989: 149, 156). There is a transcendental grammar that makes possible and shapes concrete uses of language. Now we add that technology, and not only language, can be part of such a transcendental grammar. Moreover, grammar must also be understood in a process way. Let us unpack this view by further analyzing the notion of "grammar".

\section{Transcendental Grammar (Act 4, Scene 2)}

\section{Surface Grammar Versus Depth Grammar}

When Wittgenstein uses the term "grammar," he does not mean a linguistic set of rules of how to create sentences in a certain language formally correct. He is intending a philosophical grammar, which emphasizes meaning. A formally wrong sentence can still include meaning when it is successfully applied in a communicative situation. On the other hand, even formally correct sentences could be used in an incorrect way-without a genuine meaning and sense (Kambartel 1989: 61). For example could a computer program or a bot in a social media account create a set of correct sentences without any appropriate sense of meaning. Philosophical grammar is thus more than rules of correct syntax. Wittgenstein differentiates between surface grammar and depth grammar:

In the use of words, one might distinguish 'surface grammar' from 'depth grammar'. What immediately impresses itself upon us about the use of a word is the way it is used in the sentence structure, the part of its use-one might say - that can be taken in by the ear.-And now compare the depth grammar, say of the verb "to mean", with what its surface grammar would lead us to presume. No wonder one finds it difficult to know one's way about. (Wittgenstein 2009: § 664/176e-177e)

The meaningful use of the word "meaning" is on the level of depth grammar more than its appearance in an acoustic surface or a formal rule that regulates its adequate position in a sentence. What Wittgenstein calls depth grammar is a transcendental grammar:

This finds expression in the question of the essence of language, of propositions, of thought.-For although we, in our investigations, are trying to understand the nature of language - its function, its structure-yet this is not what that question has in view. For it sees the essence of things not as something that already lies open to view, and that becomes surveyable through a process of ordering, but as something that lies beneath the surface. Something that lies within, which we perceive when we see right into the thing, and which an analysis is supposed to unearth. 'The essence is hidden 
from us': this is the form our problem now assumes. We ask: "What is language?," "What is a proposition?" And the answer to these questions is to be given once for all, and independently of any future experience. (Wittgenstein 2009: § 92/48e)

The questions what language, proposition or sentence ("German: Satz") are, is not an empirical question. Trying to answer these questions leads to insights in depth grammar, and therefore in conditions of possibilities of "any future experience". Keeping in mind our previous interpretations in terms of performance and our emphasis on process, we propose to interpret transcendental depth grammar as the grammar of human performances-performances that are more than language and enable meaningful usage of words (remember, e.g., the situation in $\$ 2$ of the Investigations).

Furthermore, in response to Wittgenstein, we now propose to expand the meaning of "transcendental" conditions of possibilities and "grammar" beyond language, thereby including technology. There is a body grammar as well as a grammar of colors or of technological artifacts. Technology, understood as tool use and as technique, is also a condition of possibility, also constitutes a depth grammar. Tool use understood as involving innate technique is a bodily sensory grammar of successful, meaningful and socially shared practice and performance. This implies that on a grammatical level, skill, understanding and knowledge belong together. Performance is about skilled use of words, body, and tools, and this is only possible in a meaningful way and in a successful way if and since there is already a socially and culturally shared whole of largely implicit know-how that forms the linguistic, bodily, and technological "grammar" which shapes and makes possible a particular use-performance. It is only possible since there is this grammar we know, but when asked about it we cannot (fully) make explicit. We knowhow, we have solutions. As individuals, we do not describe or prescribe, we do not create meaning; the grammar describes and prescribes our uses-performances, and the giving meaning and the making of meaning is always already embedded in a know-how and meaning that is given.

\section{Descriptive and Normative Performances: Wittgenstein's Philosophy and Beyond}

Does this mean that this grammar is unchangeable? Wittgenstein tends to follow a descriptive understanding of philosophy and thereby also a descriptive claim about philosophical grammar:

Grammar does not tell us how language must be constructed in order to fulfil its purpose, in order to have such-and-such an effect on human beings. It only describes, and in no way explains, the use of signs. (Wittgenstein 2009: $\S$ 496/146e)

And:

Philosophy must not interfere in any way with the actual use of language, so it can in the end only describe it. For it cannot justify it either. It leaves everything as it is. (Wittgenstein 2009: $§ 124 / 55$ e) 
From an ethical and political point of view, this seems to amount to fatalism. On the one hand, we can agree with Wittgenstein's therapeutic point that philosophers should not overestimate their syntactic power, i.e., not create formal pseudo problems, and instead stay more on the ground of real life-even if the syntax of real life is sometimes not logical. Philosophy should also not explain: "Philosophy just puts everything before us, and neither explains nor deduces anything. (...) The name 'philosophy' might also be given to what is possible before all new discoveries and inventions" (Wittgenstein 2009: $§ 126 / 55 \mathrm{e}$ ). In this "before" we meet Wittgenstein's interest in the transcendental again: philosophy, it seems, is then a performance, a way to go, which focuses on the conditions of possibility of discoveries, inventions and theories.

Now one could try to describe the shared grammar, the form of life, by means of theses. But then what is the point, since everyone would agree?

If someone were to advance theses in philosophy, it would never be possible to debate them, because everyone would agree to them. (Wittgenstein 2009: $\S$ $128 / 56 \mathrm{e})$

When philosophy proclaims a thesis, the real important work already has been done: not by philosophers, but in practice and performance. This work might result in a thesis, but cannot be replaced by the thesis as such: the thesis is made possible by a transcendental performance of understanding a new perspective after several processes of socially shared ways of trial and error. At this point the thesis is already established and not controversial; there is already a transcendental basis of culturally and socially shared knowledge, a common ground and process (or indeed a common sense). In this sense, Wittgenstein is right to say that:

In philosophy no inferences are drawn. "But it must be like this!" is not a philosophical proposition. Philosophy only states what everyone concedes to it. (Wittgenstein 2009: $§ 599 / 165$ e)

This does not mean that everyone agrees about everything; rather, it is agreement "not in opinions, but rather in form of life" (Wittgenstein 2009: $§ 241 / 94 \mathrm{e}$ ). That is, it is not an explicit agreement; Wittgenstein's claim is not about explicit but implicit knowledge. The transcendental base and process as a form of life is given and usually not doubted or debated - if it can be made explicit at all.

On the other hand, Wittgenstein does not create much room for normative performances, it seems, and at the very least we need to do work of interpretation to bring out this normative dimension. An objection to what seems Wittgenstein's fatalism can be found in Winner (1989: 16f.), who stresses the normative dimension of Wittgenstein's description:

Whatever their shortcomings, however, the philosophies of Marx and Wittgenstein share a fruitful insight: the observation that social activity is an ongoing process of world-making. [...] From this point of view, the important question about technology becomes, As we "make things work," what kind of world are we making? (Winner 1989: 17) 
If technology can be described as world making, then we can ask the normative question about what world we should be making and thus ask about the political and ethical aspects of technological performances and practices. This takes us beyond Wittgenstein. Consider for instance the ethical and societal challenges raised by talking robots and other talking machines. As they enter our everyday forms of life, what kind of world are we making? Wittgenstein discusses handcraft tools (2009: $\S$ $11 / 9 \mathrm{e}, 10 \mathrm{e})$ or industrialized technologies like steam boilers (2009: $\S$ 466/141e, 142e), mostly in analogies to language use, but always as technologies that do not talk to the users. But what about talking machines? Social robots are designed as socially interacting systems with manifold capabilities for linguistic interactions (Breazeal 2002). These social robots become active systems for verbal communication and therefore influence human linguistic habits more than non-talking tools. Engineers started designing social interaction and language. This means that values are also designed - at least very subtly_and they become, through our uses and performances, "injected" in our human language games and forms of life. Perhaps some meanings and values are amplified, whereas others are downplayed. Moreover, based on our analysis of grammar we can ask: engineers design syntax for verbal communication, but it is questionable if social robots can play language games in a richer, Wittgensteinian depth-grammatical sense. It may seem that their use of language rests mainly on a syntactical knowledge base which is epistemologically not the same as existential depth grammar or a form of life. Can those systems really play language games or follow a grammar in the nonsyntactical meaning, or are they restricted to explicit knowledge and syntactical grammar, leaving out a crucial part of transcendental grammar, of the games and the form of life? One might reply that by connecting robots to the internet and thus bringing in human meanings, engineers try to embed them in a form of life and in games, and that through use they become more embedded in such games and form of life. Moreover, social robots will influence the ways we play and maybe the rules we follow; the form of life is not entirely unchangeable, and technology plays a role in this changing. We thus acknowledge that this issue is not an either/or question. Nevertheless, in so far as robots lack a lot of implicit knowledge and do not sufficiently "hinge" on a form of life, there is still a discrepancy between the talking of the robot and the talking of humans-the latter is much richer since better anchored in a broader transcendental base, in concrete skilled human performances and in a full form of life. More generally, if there are indeed these kinds of problems, then the slogan that philosophy "leaves everything as it is" becomes ethically dangerous. As talking robots become part of everyday situations in which we (including children) play and learn language games, philosophers of technology should ask what games we should play and what world we are making; we should ethically evaluate what is happening. This happening affects the grammars forms of life, which also have a transcendental status. 


\section{Forms of Life as Transcendental Conditions and Performances (Act 4,} Scene 3)

Let us say more about the term "form of life" and the relation between language and technology. As we have shown, Winner adapts the Wittgensteinian term form of life (see also Nordmann 2015: 62-64). Technologies alter patterns of human actions and institutions, and enable variations of social roles. At the same time, technologies are embedded in, and shaped by, forms of life. But in contrast to Winner, we have anchored our use of the term in the analogy between language use and technology use (as tool use) drawn by Wittgenstein, and we propose to interpret Wittgenstein's and Winner's claim about forms of life as a transcendental one. Technology use and performance is made possible by forms of life, and these forms of life are constituted by performances-performance which, like language, have hence also a transcendental role. Thus, there is already a grammar, and this grammar is linguistic and technological-with technology understood as technique and performance. Music is again a good example since it involves these different kinds of grammar: the syntactical grammar of musical language/logic, for example, but also the grammar and games of styles, and indeed the depth grammar of an entire music culture, such as the rock culture, which constitutes a form of life. In the context of music technologies, Ihde also refers to Wittgenstein and the culturally embedded grammar of music:

Inversely, there is an analogous sense in which music also has a "grammar" and a style. No one mistakes the Rolling Stones for Mozart, neither do the more learned mistake Handel for Haydn. Yet all of these musical "grammars" are closer together than the strange "grammar" of gliding, complex, and stylized pieces of Indian music which to the beginner first often appear as not even "music". (Ihde 2007: 157)

Style and grammar in turn depend on techniques and games like playing distorted e-guitar (Rolling Stones) and classical orchestra (Mozart) or different tonal systems and instruments like sitars (Indian Raga music). Grammar and technique, social sharing and language, characterize the embodiment of musical cultures. More generally, we can conclude that there is already a grammar which shapes our use of technologies, in music and elsewhere. But, interestingly, this also holds vice versa: technology also alters our language (use) and hence our thinking. This is how Winner summarizes the value of Wittgensteins thoughts for philosophy of technology:

Wittgenstein points to a vast multiplicity of cultural practices that comprise our common world. Asking us to notice "what we say when," his approach can help us recognize the way language reflects the content of technical practice. It makes sense to ask, for example, how the adoption of digital computers might alter the way people think of their own faculties and activities. If Wittgenstein is correct, we would expect that changes of this kind would appear, sooner or later, in the language people use to talk about themselves. (Winner 1989: 15) 
Another way of saying this, is that technologies - understood as tool use, technique, and performance-shape the grammar of thinking. Hence, considered from the perspective of transcendental grammar, there are deep parallels and connections between language and technology. In line with Wittgenstein, we must reject dualistic thinking in this matter. Language and technology, bound together in performance and in transcendental processes, should not be separated. This is also applicable to the relation between music and language (or logic). As Ihde puts it:

There is a sense in which, phenomenologically, spoken language is at least as "musical" as it is "logical," and if we have separated sound from meaning, then two distinct directions of inquiry are opened and opposed. But in voiced word music and logic are incarnate. No "pure" music nor "pure" meaning may be found. (Ihde 2007: 157)

In contrast to Ihde, however, we argue in a more confidently Wittgensteinian vein that musical grammars and cultural embodiments in music, but also music technologies, constitute transcendental forms of life. For example, the e-guitar becomes a condition of possibility of how to talk with and about music. Of course there is a concrete artifact, such as a Stratocaster guitar or tube amplifier. But there are also concrete skills that are enabled by these instruments and at the same time shape the possibilities of how to use it - what we called "innate technique" — and on the link between these skills and techniques and the form of life as a transcendental condition. Before a musician starts playing and performing, there is already a form of life which provides grammars that make possible the playing and shape particular performances, techniques, and styles. These grammars can change. Consider the history of rock music, understood as a history of technology-the history of the electric guitar. For instance, initially the transcendental forms of life of classical musicians shaped the performances of many early e-guitarists. But as more the electric guitar became an established everyday life instrument, the more younger guitarists developed and adopted own ways of playing these instruments-mostly in rock'n roll like styles. These styles became step by step new conditions of possibilities, both in performing music and in performing the own life. With the different technology, different skills and techniques, musical styles, and language, there was not only new music; a new form of life emerged. The 1960th hippie movements or later punk were examples of this; as (sub)cultures they can be seen as transcendental conditions: a holistic socially shared grammar of how to make music, talk to each other, and lead one's life, which itself has the character of process and performance. Transcendental performances and form(s) of life holistically conditioned technological practices, games, and activities like eating, wearing clothes, hair styles or body languages, in which people became enmeshed. The form of life became varied and changed. Wittgenstein also points to diversity:

There are countless kinds; countless different kinds of use of all the things we call "signs," "words," "sentences". And this diversity is not something fixed, given once for all; but new types of language, new language-games, as we may say, come into existence, and others become obsolete and get forgotten. [...] The word "language-game" is used here to emphasize the fact that the 
speaking of language is part of an activity, or of a form of life. (Wittgenstein 2009: $§ 23 / 14 \mathrm{e}, 15 \mathrm{e})$

In this paper, we emphasized that technology, understood as tool use and as technique and skill, plays a crucial performative and transcendental role in this kind of change. The mentioned activities depend on settings, circumstances and concrete situations that are shaped by technology as a transcendental condition of possibility. Consider what Wittgenstein writes about chess:

An intention is embedded in a setting, in human customs and institutions. If the technique of the game of chess did not exist, I could not intend to play a game of chess. (Wittgenstein 2009: § 337/115e)

This can be generalized to all technological practices. Technology plays a transcendental role here: there is already a form of life, there is already a grammar, which is at the same time linguistic-cultural and technological-cultural, and which makes possible and shapes particular moves, performances, and games.

\section{Conclusion: Wittgenstein as a Philosopher of Technology (Act 5 and Final Act)}

We used Wittgensteinian terms such as games and form of life, but we also introduced new terms such as innate technique and transcendental technology and performance to reflect on how technologies are more than artefacts or functions. As technologies are used, as we perform with technologies, as we learn skills and technique in the process of using technologies, technologies are shaped and made possible by larger grammars, by a form of life, and are in turn also constitutive of this transcendental conditions and transcendental whole, understood as process and performance. This means that technology, as tool and technique, is always more than a mere instrument. Deeply linked to our shared meanings and shared performances, it shapes our activities, our thinking, and our existence, and cannot be isolated from our form of life. Neither can we isolate it from use of language and from logic-if a distinction is meaningful at all. Language and technology are strongly entangled: in use and technique, and in their role as transcendental conditions.

Based on the previous arguments and interpretations, we therefore propose to revise current approaches to phenomenology and hermeneutics of technology, including postphenomenology, in a way that takes more into account the Wittgensteinian insight that technology is not just about 'things' but also about use of things and performance with things. We believe that this approach opens up an approach to understanding technologies that (1) relates particular technologies to the activities, games, and form of life they are part of and on which their use and performance depends, (2) pays more attention to, and acknowledges, the importance of skill, technique and implicit knowledge in the use of tools, and (3) can be helpfully connected to a transcendental interpretation of Wittgenstein's concepts games and forms of life. 
With our example of talking robots, we have also suggested that this approach can inform an ethics and politics of technology, but more research is needed to develop this point. Further work is also needed to elaborate a Wittgensteinian epistemology of technology. Research that further develops and applies the interpretations and arguments in this essay may include topics such as time, finitude and technology, technology and games, technology skills and implicit knowledge, technology and language, artistic performance, epistemology of music, ethics of technologies, relations between ethical, philosophical and technological grammar, relations between Wittgenstein and other philosophers (Heidegger, Husserl, Merleau-Ponty, Plessner, etc.), engagement with thinkers from the social sciences such as Latour, and so on. For example, one may compare Heidegger's notion of enframing (Heidegger 1977) to Wittgenstein's notion 'form of life'. We suggest that the concept 'form of life' could serve to capture two kinds of approaches: one that employs the notion of 'enframing,' which refers to a more general meaning of technology and technological culture, and one that zooms in on the uses and meanings of specific technologies. We can try to understand our modern form of life and we can study the link between a specific technology-in-use and larger technological-cultural wholes. The term 'form of life' can thus help to render both approaches compatible.

As these examples suggest, our interpretations and arguments are not only relevant to philosophy of technology; the topic of Wittgenstein and technology deserves wider attention in the philosophical community. In the course of our paper, we have engaged with Wittgenstein and with important epistemological questions concerning knowledge and doubt, and we have highlighted how Wittgenstein and our interpretations of Wittgenstein stand in the philosophical tradition. With a radical intention and gesture, we have been presenting a transcendental interpretation which constructed Wittgenstein as a continuator of Kant's critical project, and placed our response to Wittgenstein within that history of thinking. In these and other ways, the question of technology as use and technique (and its relation to language) turns out to be a fundamental philosophical question that is not only owned by a specialized subdiscipline, but that is central to philosophy as such.

Acknowledgements Open access funding provided by University of Vienna.

Open Access This article is distributed under the terms of the Creative Commons Attribution 4.0 International License (http://creativecommons.org/licenses/by/4.0/), which permits unrestricted use, distribution, and reproduction in any medium, provided you give appropriate credit to the original author(s) and the source, provide a link to the Creative Commons license, and indicate if changes were made.

\section{References}

Augustine. (1955). Confessions (A. C. Outler, Trans.), First published MCMLV, library of congress catalog card number: 55-5021, This book is in the public domain. It was scanned from an uncopyrighted edition. Harry Plantinga. http://faculty.georgetown.edu/jod/augustine/conf.pdf [last visited at November 15, 2016]. 
Benton, T. (2002). Wittgenstein, Winch and Marx. In G. N. Kiching \& N. Pleasants (Eds.), Marx and Wittgenstein: Knowledge, morality and politics (147ff.). London: Routledge.

Birnbacher, D. (1995). Künstliches Bewusstsein. In Th. Metzinger (Ed.), Bewusstsein: Beiträge aus der Gegenwartsphilosophie. Paderborn: Mentis.

Bloor, D. (1983). Wittgenstein: A social theory of knowledge. New York: Columbia University Press.

Bloor, D. (1997). Wittgenstein, rules and institutions. London: Routledge.

Breazeal, C. L. (2002). Designing sociable robots. Cambridge: The MIT Press.

Coeckelbergh, M. (2012). Growing moral relations. Critique of moral status ascription. Basingstoke: Palgrave MacMillan.

Coeckelbergh, M. (2015). Language and technology: Maps, bridges, and pathways. Berlin: Springer.

Coeckelbergh, M. (2017). Using words and things: Language and philosophy of technology. Abingdon: Routledge.

Collins, H. M. (1974). The TEA set: Tacit Knowledge and scientific networks. Science Studies, 4, $165-186$.

David, P. A. (1985). Clio and the economics of QWERTY. American Economic Review, 75(2), 332-337.

Dreyfus, H. (1972). What computers can't do: The limits of artificial intelligence. New York: MIT Press.

Feuerbach, L. (1983). Grundsatze einer Philosophie der Zukunft. Frankfurt: Vottorio Klostermann.

Friesen, H., \& Berr, K. (2004). Technik und Bewusstsein. Einige kritische Überlegungen zur Ontologie des künstlichen Geistes. In K. Kornwachs (Ed.), Technik-System-Verantwortung (233-244). Münster: LIT.

Funk, M. (2010). Verstehen und Wissen. Ludwig Wittgensteins Philosophie der Technik. In L. Leidl \& D. Pinzer (Eds.), Technikhermeneutik. Technik zwischen Verstehen und Gestalten (75-88). Frankfurt am Main a.o: Peter Lang.

Funk, M. (2015). Zwischen Genetik und klassischer Musik. Zur Philosophie sinnlichen Wissens. In C. Asmuth \& P. Remmers (Eds.), Ästhetisches Wissen (Berlin studies in knowledge research) (Vol. 7, 249-288). Berlin: Walter de Gruyter.

Funk, M., \& Coeckelbergh, M. (2013). Is gesture knowledge? A philosophical approach to the epistemology of musical gestures. In H. De Preester (Ed.), Moving imagination-Explorations of gesture and inner movement in the arts. (Advances in consciousness research) (Vol. 89, 113-132). Amsterdam: John Benjamins Publishing Company.

Gier, N. (1980). Wittgenstein and forms of life. Philosophy of the Social Sciences, 10(3), 241-258.

Gier, N. (1990). Wittgenstein's phenomenology revisited. Philosophy Today, 34(3), 273-288.

Heidegger, M. (1977). The question concerning technology. In The question concerning technology and other essays (W. Lovitt, Trans.) (3-35). New York: Harper \& Row.

Ihde, D. (1979). Technics and praxis. Dordrecht a.oA: Philosophy of Technology.

Ihde, D. (1991). Instrumental realism. The interface between philosophy of science and philosophy of technology. Bloomington: Indiana University Press.

Ihde, D. (2006). Forty years in the wilderness. In E. Selinger (Ed.), Postphenomenology: A critical companion to Ihde (267-290). Albany: State University of New York Press.

Ihde, D. (2007). Listening and voice. Phenomenologies of sound (2nd ed.). New York: SUNY Press.

Irrgang, B. (2001). Technische Kultur. Instrumentelles Verstehen und technisches Handeln. Philosophie der Technik Bd. 1. Paderborn/München/Wien/Zürich: Schöningh.

Irrgang, B. (2007). Hermeneutische Ethik. Darmstadt: WBG.

Kambartel, F. (1989). Philosophie der humanen Welt. Abhandlungen. Frankfurt a.M: Suhrkamp.

Keicher, P. (2008). Heidegger und Wittgenstein zur ontologie und Praxis der Technik. In A. Pichler \& H. Hrachovec (Eds.), Wittgenstein and the philosophy of information, Vol.1. Proceedings of the 30 international Ludwig Wittgenstein symposium (181-193). Kirchberg am Wechsel, Austria 2007, Heusenstamm: Ontos.

Kogge, W. (2015). Die Frage nach den Kriterien: Wittgensteinische perspektiven für die Technikphilosophie. In: G. Gerhard, G., Petra, K. Andreas, N. Alfred, \& H. Christoph (Eds.), Ding und system, Jahrbuch Technikphilosophie (93-115). Diaphanes, Zurich.

Lynch, M. (1993). Scientific practice and ordinary action: Ethnomethodology and social studies of science. Cambridge: Cambridge University Press.

Lynch, M. (1997). Theorizing practice. Human Studies, 20(3), 335-344.

Noë, A. (2004). Action in perception. Cambridge, MA: MIT Press.

Nordmann, A. (2002). Another new Wittgenstein: The scientific and engineering background of the Tractatus. Perspectives on Science, 10(3), 356-383.

Nordmann, A. (2015). Technikphilosophie zur Einführung. Hamburg: Junius. 
Pinch, T. (2006). Voices in the electronic music synthesizer: An essay in honor of Don Ihde. In E. Selinger (Ed.), Postphenomenology: A critical companion to Ihde (49-65). Albany: State University of New York Press.

Pinch, T. J., \& Trocco, F. (2004). Analog days. The invention and impact of the Moog synthesizer. Cambridge, MA: Harvard University Press.

Polanyi, M. (1958). Personal knowledge. Towards a post-critical philosophy. Chicago, IL: The University of Chicago Press.

Polanyi, M. (2009). The tacit dimension. With a new foreword by Amartya Sen. Chicago/London: The University of Chicago Press.

Poser, H. (2004). Entwerfen als Lebensform. Elemente technischer Modalität. In K. Kornwachs (Ed.), Technik-System-Verantwortung (561-575). Münster: LIT.

Rentsch, T. (2003). Heidegger und Wittgenstein. Existential-und Sprachanalysen zu den Grundlagen philosophischer Anthropologie. Stuttgart: Klett-Cotta.

Shapins, S., \& Schaffers, S. (1985). Leviathan and the air-pump: Hobbes, boyle, and the experimental life. Princeton: Princeton University Press.

Soler, L., \& Zwart, S. D. (2013). Editorial introduction: Collins and tacit knowledge. Philosophia Scientiae, 17(3), 5-23.

Sterrett, S. (2005). Wittgenstein flies a kite. New York: Pi Press.

Varela, F. J., Thompson, E., \& Rosch, E. (1997). The embodied mind. Cognitive science and human experience (sixth printing). Cambridge: MIT Press.

Winch, P. G. (1958). The idea of a social science and its relation to philosophy. London: Routledge \& Kegan Paul.

Winner, L. (1986). The whale and the reactor: A search for limits in an age of high technology (1989). Chicago: University of Chicago Press.

Wittgenstein, L. (1969). On certainty (G. E. M. Anscombe, \& von Wright, G. H. Eds., D. Paul, G. E. M. Anscombe, Trans.). Oxford: Basil Blackwell.

Wittgenstein, L. (2009). Philosophische Untersuchungen. Philosophical investigations (P. M. S. Hacker, \& J. Schulte Eds., G. E. M. Anscombe, P. M. S. Hacker, \& J. Schulte, Trans.). Revised 4th edition. Chichester UK: Blackwell Publishing. 